\title{
Disaster Series: The Use of Information for Wildland Fire and the NICU: Combined Evacuation and Sheltering
}

Daved van Stralen, MD, FAAP, Sean D. McKay, Thomas A. Mercer, RAdm, USN

\begin{abstract}
Wildland fire threatens the hospital, evacuation routes, and even the use of vehicles. Smoke-filled air endangers the neonate inside the NICU or ambulance, while poor visibility can ground helicopters. The wildland fire environment is continuously changing from fire behavior determined by topography, fuel characteristics, and wind. This creates a fire environment of poor air quality and road closures or congestion-the decision to evacuate or shelter changes, sometimes by the hour. Therefore, NICUs planned simultaneously to evacuate and shelter. This review revealed two different systems for decisions and coordination of evacuation depending on governmental support. Regardless, NICU staff were the ones making specific decisions and preparations for evacuation or sheltering.
\end{abstract}

\section{"Wildland fire threatens the hospital, evacuation routes, and even vehicles, whether air or ground. Smoke-filled air endangers the neonate inside the NICU or riding in an ambulance. Rural hospitals several hours from a receiving hospital have but a few local ambulances available for evacuation."}

\section{Introduction}

Wildland fire threatens the hospital, evacuation routes, and even vehicles, whether air or ground. Smoke-filled air endangers the neonate inside the NICU or riding in an ambulance. Rural hospitals several hours from a receiving hospital have but a few local ambulances available for evacuation. Poor visibility from smoke prevents helicopters from flying. Government agencies protect life and property, allocating limited resources to save a city from fire, and may requisition helicopters or ambulances, preventing their use by the NICU $(1,2)$. An approaching fire means the Neonatologist must simultaneously prepare to evacuate the NICU and shelter in place. Rapid evacuation of the NICU is labor-intensive over hours $(1,2)$. To shelter in place, the NICU brings in extra staff and stockpiles supplies.

Of course, it is prudent to prepare to evacuate from an oncoming fire. Until you step outside and realize the infant will travel in an ambulance for several hours, much through smoke, and there are only two ambulances in town with insufficient neonatal-trained staff to accompany the infants. Sheltering does make sense keep the neonates as a group with an intense concentration of neonatal specialists in nursing, pharmacy, and respiratory care with an ample stock of supplies and extra equipment - until soot comes through the ventilation system, the roads close from fire, and returning staff are caught in the fire.

\section{"These are the situations when preparations to evacuate inform the decision to shelter, and preparations to shelter inform the decision to evacuate. In the episodes described below, Neonatologists and administrators consistently prepared to evacuate and shelter at the same time."}

These are the situations when preparations to evacuate inform
the decision to shelter, and preparations to shelter inform the deci-
sion to evacuate. In the episodes described below, Neonatologists
and administrators consistently prepared to evacuate and shelter
at the same time. Fires change direction and speed in minutes.
You can be safe one moment and endangered the next. The deci-
sion to evacuate is a constant decision continuously incorporat-
ing changing information. In a sense, preparing for wildland fire,
simultaneous evacuation and sheltering, is to prepare to fail. The
organization not prepared to fail will fail. We reviewed published accounts containing first-person experiences (3-5). From these articles, we extracted and collated the actions and words of participants. Rather than listing models and tools that the participants stated they had used, we describe how they used the models and tools. This follows James P. Spradley's description of culture - how people use social knowledge to interpret the world (6).

How people use social knowledge is how they enact future states (7), critical processes for the event that abruptly collapses our sensemaking (8). Looking at the actions described in this paper as an outsider can facilitate the "I wouldn't have done that" response. This is not hindsight but rather a thoughtful discourse to reach a useful, effective conclusion. What that approach lacks is one of the necessary High-Reliability Organizing (HRO) values identified by two of the authors (DvS, TAM) as required to make HRO operational (9), empathy - "That could be me."

In the Neonatology Today: Disaster Series, we present High-Reliability Organizing (HRO) as a means to understand decisions

NEONATOLOGY TODAY is interested in publishing manuscripts from Neonatologists, Fellows, NNPs and those involved in caring for neonates on case studies, research results, hospital news, meeting announcements, and other pertinent topics.

Please submit your manuscript to: LomaLindaPublishingCompany@gmail.com 
better and prepare for evacuation or sheltering in place due to an approaching wildland fire. In the setting of wildland fire, the HRO's response moves toward High-Reliability Operations.

\section{"Wildland fire, irrespective of the type of vegetation, is demanding to manage, the resources complex to coordinate, and the consequences catastrophic for wildland firefighters and the public."}

\section{The Wildland Fire Environment}

There are two types of firefighters: structure firefighters and wildland firefighters. While the lay community uses the terms wildfire, forest fire, or brushfire, the professional term is 'wildland fire.' Regardless of whether grass, brush or the forest is on fire, the grim results are destroyed homes and fatalities. Wildland fire, irrespective of the type of vegetation, is demanding to manage, the resources complex to coordinate, and the consequences catastrophic for wildland firefighters and the public.

The Incident Command System came about from the challenge of rapidly coordinating 95,000 professional firefighters from 500 separate departments and agencies throughout California in 1970. During thirteen days in Southern California, 773 wildland fires destroyed 722 homes and killed sixteen people (10). The loss of fourteen wildland firefighters in the 1994 South Canyon Fire (11) led to the incorporation of Lessons Learned through establishing the national Wildland Fire Lessons Learned Center's (WFLLC), Tucson, AZ in 2002. Later, with consultation from Karl Weick and Kathleen Sutcliffe, the WFLLC incorporated HRO into wildland fire management (12).

Wildland fires increasingly affect hospitals due to the increase in Wildland-Urban Interface, a consequence of the growth of communities into and within forested areas. The severity and threat of approaching wildland fire come from smoke, highway access, and the risk of the hospital catching fire. Winds, humidity, and vegetation drive these risks. It appears prudent to evacuate from a distance, except that evacuation places a load on staffing and transport resources and is time-consuming.

\section{Fire Behavior}

Fire behavior describes the movement and intensity of wildland fire and is determined by various elements, including topography, fuel characteristics, and wind (13). Familiarity with fire behavior, combined with information about the fire's proximity, winds, road closures, and air quality outside and inside the facility, are necessary for safe and effective decisions regarding evacuation versus shelter in place.

Fire danger ratings assess the potential for wildland occurrence, spread, and difficulty to suppress (14). The greatest contributions to fire danger are wind speed and moisture content of vegetation (fuel). Temperature and relative humidity determine fuel moisture content.

Topography describes the hospital's elevation, nearby slopes, and their orientation, the direction nearby slopes face. South-facing slopes are hotter and drier than north-facing slopes. In valley bottoms, nocturnal air temperatures are coolest and humidity highest (14).

Fuel characteristics influence the intensity of the fire, with fires burning in grass, shrubs, and tree branches having less intensity than crown fires burning through the tops of trees.

Winds aid fire spread by causing flames to lean closer to unburnt fuel, supplying oxygen, and carrying away moist air (14), influencing a fire's direction and increasing its intensity. Local residents will be familiar with local winds and 'critical' winds, which are regional scale (synoptic) winds. Although this seems pedantic, appreciating these differences explains the uncertainty of an approaching fire's path and the great speed the approaching fire can sustain.

Critical winds dominate the fire environment (15):

- Downslope winds follow air pressure gradients down a geographic slope. Examples are the Chinook Winds off the eastern Rocky Mountains and California's Santa Ana Winds from a high-pressure centered over Utah's central plateau region.

- Downslope winds become hotter, drier, and faster from acceleration between mountain ranges and through passes.

- Frontal winds follow the pressure gradient between weather fronts in the mountains and Great Plains of the US.

- $\quad$ On the leeward sides of mountains, Foehn winds become dry and hot after moisture is lost, rising over the mountain range then re-warmed as the winds move downslope.

The characteristics of regional scale (synoptic) winds explain their danger, why they are considered critical winds. Synoptic scale winds have horizontal lengths over 600 miles (1000 km), seasonal occurrences, low humidity, and expected, sustained wind speeds (>30 mph, easily exceeding $40 \mathrm{mph}$ for Santa Ana winds). In a few hours, these winds can dry vegetation to the level of high fire hazards.

\section{"The characteristics of regional scale (synoptic) winds explain their danger, why they are considered critical winds. Synoptic scale winds have horizontal lengths over 600 miles (1000 km), seasonal occurrences, low humidity, and expected, sustained wind speeds (>30 mph, easily exceeding 40 mph for Santa Ana winds)."}

Humidity, relative humidity, and temperature influence fire danger through their effect on the moisture content of fuels (14).

\section{The Fire Environment}

Proximity and velocity of fire. As the fire approached, residents evacuated their homes, increasing road congestion (4). The approaching fire led neonatologists and hospital administrators to prepare for evacuation while more closely evaluating whether to shelter in place (3-5).

Winds, as threats to transportation, became a consideration for evacuation of one NICU. For another NICU in the same fire, the wind changed the direction of the fire (5).

Road closures. Fires can easily jump interstate highways, and the radiant heat from burning trees can threaten the occupants of vehicles. Evacuating residents will congest smaller rural roads. Road closures and congestion interfered with the ability of re- 
called healthcare providers to return to the facility (4) or evacuate facilities (5).

Air quality. Smoke and air quality have been identified as a significant problem for the NICU (16). "Smoke-filled air entered the ED's and hospital ventilation systems and triggered bronchospasms in some staff members. Many hospitals treated employees for smoke-related illnesses" (4). "Despite air scrubbers in place, air quality was poor, and minimizing the amount of soot and debris inside the facility was difficult" (3). "You could see smoke in the hospital, and it was hazy outside" (5). The thickness of the smokedarkened skies and decreased visibility, grounding aviation resources (4).

Information from the environment is necessary for safe and effective decisions to evacuate or shelter in place. The strongest influences mentioned in the narratives were the fire's proximity, the severity of winds, road closures, and the air quality outside and inside the facility (3-5).

\section{"Information from the environment is necessary for safe and effective decisions to evacuate or shelter in place. The strongest influences mentioned in the narratives were the fire's proximity, the severity of winds, road closures, and the air quality outside and inside the facility (3-5)."}

\section{Evacuate and/or Shelter}

These three wildland fires revealed two different systems for decisions and coordination of evacuation depending on governmental support. Regardless of regional or government plans, the healthcare providers in the facility were the ones making specific decisions and preparations for evacuation or sheltering.

Two facilities are in the same county, San Diego, CA, where the county Office of Disaster Preparedness coordinates evacuation, including transportation vehicles and receiving hospitals $(3,4)$. These operations included close consultation between the affected hospital and the county, including the type and level of care necessary for the patient.

The two NICUs, without government coordination, decided with their hospital incident command and leadership. Part of a regional healthcare system, one hospital initiated an internal emergency that rapidly progressed to their system-wide incident command. The other NICU in the Level 1 Evacuation Zone prepared to evacuate with discussion among their hospital leadership. Neither hospital administration had experience with an operation of this magnitude. The Neonatologists smoothed the process through their personal relations with the receiving Neonatologists. Though not easy, it was effective (5). The other NICU was part of a healthcare system with a larger medical center and a regional medical center.

\section{Discharge Patients}

Physicians and staff responded to assist either by being recalled or arriving voluntarily. Physicians began patient discharge for those who could be released and to work toward the evacuation of the other patients (3-5). One NICU discharged infants to parents in the morning after evacuation (5).

\section{NICU Evacuation (5)}

Encroaching fires made the area of the hospital a Level 1 evacuation zone; the Neonatologists prepare to move patients. Neonatal nurses prepared bags of necessary supplies for each infant:

Stethoscope, bulb suction, blood pressure cuff, thermometer, diapers, wipes, PPE, emergency code med sheet, formula, breast milk, feeding tube, IV pumps, supplies for ordered labs, daily progress note, face sheet with parent contact information and other supplies as needed.

That evening, concern about winds led the medical staff to decide for evacuation to area hospitals. The 14 neonates would be among the first evacuated as "red" status, that is, patients who could not be moved by wheelchair. The neonatologists immediately began to arrange transports to avoid an emergent Level 2 evacuation of the babies. Without regional coordination, the Neonatologist described the patient to a potential receiving neonatologist and requested acceptance. Personal relationships with area neonatologists smoothed the process with the neonates distributed evenly among area NICUs based on family's location. Transfers of eleven infants would start that night, with three infants discharged in the morning.

\section{"Personal relationships with area neonatologists smoothed the process with the neonates distributed evenly among area NICUs based on family's location. Transfers of eleven infants would start that night, with three infants discharged in the morning."}

After arranging placement, the Neonatologists coordinated specialized ambulance transport teams. The first baby was evacuated at $2140 \mathrm{~h}$, and the last baby left at $0410 \mathrm{~h}$. The three infants were discharged to their parents. The wind changed, but air quality in the NICU was still poor, with smoke visible in the hospital.

The area hospitals had access to a shared electronic medical record (EMR).

With the evacuation under relatively controlled conditions, eleven infants were transferred over $6 \frac{1}{2}$ hours, coordinated with specialized and skilled transport teams.

\section{Evacuation with Maternity Patients (3)}

One hospital without a NICU evacuated babies from the nursery as ambulatory mother-baby dyads.

On the first day of a nearby fire with Santa Ana winds gusting to 80 $\mathrm{mph}$, the county opened the Emergency Operation Center (EOC). With the fires spreading, the EOC notified the hospital to initiate its Incident Command Center. The hospital administrators planned for evacuation with approaching fire, exposure to debris, and poor air quality. About $2200 \mathrm{~h}$, disaster equipment was readied, patient records copied, and off-duty physicians arrived to discharge patients.

By 0300h the following day, the EOC advised hospital administrators they could only give a two-hour window to evacuate. Residents began arriving at the hospital seeking a haven for themselves, their families, and their pets. With poor environmental air 
quality, the hospital air scrubbers became inadequate - smoke, soot, and debris entered the facility creating poor air within the hospital. By 0800h, with the possibility of the fire breaching hospital grounds, the hospital administrators decided to evacuate the hospital.

\section{"The county EOC directed staging for transportation with ambulances staged at a local fire station and school buses staged in a nearby parking lot. Ambulatory patients evacuated by bus, egressing through the front entrance of the hospital."}

The county EOC directed staging for transportation with ambulances staged at a local fire station and school buses staged in a nearby parking lot. Ambulatory patients evacuated by bus, egressing through the front entrance of the hospital. A manager of the medical, surgical, and telemetry units directed the process. Each bus transported five patients escorted by one certified nursing assistant and one RN and any needed medical supplies, oxygen tanks, and emesis basins. Family members could accompany patients and assist in calming their anxiety. Ambulatory patients included postpartum mother and baby combos.

Patients needing a gurney or wheelchair were evacuated by ambulance through the ED coordinated by a paramedic supervisor and ED manager. One ambulance could transport two patients, one gurney patient in the back and one wheelchair patient in front

\section{Evacuate then Sheltered (5)}

At $1100 \mathrm{~h}$, a manager's spouse calls her about the fires. In the incident command meeting, she becomes the Emergency Preparedness Manager. A Neonatologist hearing of the proximity of the fire arrives to assist. The hospital declared an internal emergency at $1251 \mathrm{~h}$, which quickly expanded to a system-wide incident command for the three hospitals. Two and a half hours later comes the call for all available providers to return to the hospital.

The NICU team begins planning for the evacuation of 16 neonates. Without regional coordination, Neonatologists begin calling NICUs, the nearest 2.5h away. The NICU team creates an evacuation list for the respiratory support, equipment, and staff each infant will need for transport. Bedside nurses create supply bags for each neonate for monitoring, routine care, emergency treatment, documents, and other supplies as needed.

Fires close roads to the north and south. The evacuation of residents congests the open roads-poor visibility from smoke grounds air transport. The ICU is isolated from the rest of the state. They will have about an hour's notice to evacuate. The babies cannot be transported one at a time. Neonatologists and NICU staff, therefore, create their own extemporaneous triage system.

Pink neonates ( 6 infants) are the most acute receiving the highest level of support and will be evacuated by ambulance with two neonates per ambulance. Two staff members will travel in the ambulance. Because the main NICU is on the ground floor, the neonates can be directly taken to the ambulance.

Yellow neonates (2 infants) are intermediate and will be evacuated by bus or private car with the driver (driver, not a team member). Accompanying staff will be a nurse and respiratory therapist or Neonatologist. From the main NICU, they can also be moved directly to the transport vehicle.
Green neonates (8 infants) are the feeder growers, babies without other medical concerns. Their evacuation can be staffed by a nurse and respiratory therapist or Neonatologist using a bus or private car (driver, not a team member). Because they are on the second floor, they will be carried down the stairway.

The day-shift staff has been held over to work with the night-shift staff. The three neonatologists on service are in-house, with four others on standby. The standby neonatologists are ready to evacuate with cars and car seats.

The winds shifted away from the hospital; the fire department contained the fire. The NICU did not evacuate.

\section{Prepare to Evacuate then Sheltered (4)}

The wildland fire started in the area. Two days later, it became more extensive, threatening two larger hospitals with NICUs. The county EOC opened, $0530 \mathrm{~h}$.

The next day, $0700 \mathrm{~h}$, a nurse calls. She reports she is unable to work because her house is threatened and her family is endangered. At $0800 \mathrm{~h}$, another nurse on duty calls, her house is "in the line of fire." She is sent home. At 0900h hospital, administrators initiate "Disaster Standby" to activate additional resources. At 0915h, the Emergency Care Center (ECC) Director activates a full disaster response. All hospital staff are in full preparation for the approaching fire.

At $1200 \mathrm{~h}$, hospital administrators learn the fire is continuing to move toward the hospital and could "jump the freeway." Central Supply delivers oxygen masks, nebulizers, and $\mathrm{O}_{2}$ tanks to the ED. Pharmacy stands by with additional pulmonary medications.

At $1300 \mathrm{~h}$, hospital administrators decide to prepare evacuation. The NICUs for both hospitals would evacuate neonates to the USNS Mercy, the Military Sealift Command hospital ship based in San Diego. The Mercy is about 10 miles from the fire. The NICUs will pool their efforts, using evacuated staff to escort neonates and ensure all NICU patients will be transferred as a group.

At $2000 \mathrm{~h}$, the winds change direction, moving the fire into the mountains. Firefighters sufficiently contain the fire; there is no evacuation. Staff, however, remain ready to evacuate.

The alert continued until the next day.

\section{The Decision to Evacuate}

The decision to prepare for evacuation or to shelter consumes staff time and resources. It is not a light decision. Communication with government public safety services and receiving NICUs occupies the attention of senior managers and administrators and phone lines and radio frequencies. Equipment and supplies for each neonate will be gathered by other staff while others will prepare medical records for transfer. To shelter involves engineering services to assess the strength of the physical structure and reliability of power and water.

The increasing proximity of the fire drove the decision for the four facilities. One NICU planned for evacuation while awaiting sufficient information on whether to evacuate or shelter. Another NICU in the Level 1 Evacuation Zone initially evaluated neonate evacuation to a major city (5). A third hospital conferred with the county and city officials regarding methods for safe evacuation and the limits on resources due to the size of the fire. They would have a two-hour window to move their patients (3). The fourth hospital decided to prepare for evacuation (4).

While the decision to evacuate was uniformly influenced by the proximity and behavior of the fire, one facility specifically stated internal air quality contributed to their decision to evacuate (3). All described the negative effects of environmental and internal air quality on the care for infants (3-5). 
In one county, the county emergency operations center provided the hospitals with a list of accepting hospitals, number of patients that can be accepted, and level of care available (3). If there were limited space at receiving NICUs, medical staff at one facility discussed opening a Level II NICU in a safe area (5). One facility categorized neonates as "unable to use wheelchair transport," moving them into the group to be evacuated first (5).

\section{Call for Receiving Facilities}

Neonatologists for the two NICUs in the same fire and without regional coordination called other NICUs to determine bed availability. One of the NICUs later sheltered while the other evacuated (5). In another wildland fire, the Neonatologist believed that calling the operation center rather than directly contacting the NICUs would have improved regional coordination and prevented overlapping requests (16). The two California hospitals described above deferred to the county EOC. Managers had predetermined bed locations and the number and types of patients transferred to each hospital (3).

In previous fires, this communication was lacking, with at least one instance of babies arriving at the receiving hospital without notification or acceptance (16).

\section{"Evacuation consumes staff and hours of time, while sheltering exposes the infants to grave risk. One NICU was faced with evacuating infants through smoke and dangerous air quality for a $21 / 2$ hour drive over congested roads that may abruptly close due to fire activity."}

\section{Evacuation}

Evacuation consumes staff and hours of time, while sheltering exposes the infants to grave risk. One NICU was faced with evacuating infants through smoke and dangerous air quality for a $21 / 2$ hour drive over congested roads that may abruptly close due to fire activity. They were without aviation resources. The circumstances had significant contributions to their decision to shelter in the hospital (5). Another facility had decided to move ahead with evacuation but changed to sheltering seven hours later with fire containment (4). Even then, the staff remains ready to evacuate.

Because the decision to shelter came after the decision to evacuate, the sheltering NICUs were poised to evacuate rapidly.

\section{Transportation}

Sleds modified for infants and capable of containing a ventilator have been used to evacuate infants, including descending stairways. Aprons have been used, but one hospital did not find they worked well (16).

NICUs evacuating infants have relied on ambulances, buses, and private cars using bassinets or car seats for all three modes when possible. The use of cars could free ambulances to evacuate sicker infants (16). Without regional coordination, administrators at a rural NICU coordinated specialized transport teams for the NICU. The first baby left in the late evening, and the last baby evacuated in the early morning - eleven babies in $6 \frac{1}{2}$ hours.

NICUs that had wildland fire exposure but did not evacuate had planned to use general ambulances for transport. Two in the sur- vey would use neonatal transport teams. There would also be planned reliance on helicopter transport (16).

Bassinets rather than open cribs for ambulance transport could prevent infants from sliding around, though it did not happen during a fire evacuation. The ability to support oxygen administration would also be helpful (16).

The county EOC coordinated transport for a larger hospital, but healthcare providers and administrators were responsible for gathering and preparing the patients. The EOC staged ambulances at a fire station and school buses in a nearby parking lot. A paramedic supervisor and ED manager coordinated ambulance transport through the ED while a medical unit manager coordinated bus transport through the hospital's front entrance. Postpartum mothers with their babies traveled on buses (3).

\section{"Medical care is accustomed to 'well- defined problems." The problems in a disaster are not only ill-defined; they are embedded in the environment with the free exchange of energy. Emergency plans presuppose effective courses of action."}

Two facilities were prepared for transport then sheltered. The distant, rural NICU retained day-shift staff, and the three Neonatologists on service came to the NICU for transport preparation and sheltering if necessary. The Neonatologists and nursing staff organized into eight teams with two patients per team for a $2 \frac{1}{2}$ hour road trip by ambulance, bus, or car (5). A driver that is not a team member would drive any private car. The NICU on the ground floor provided had direct outside access to the transport vehicle. Feeder growers on the second floor could be carried downstairs to the awaiting vehicle.

\section{Staffing and Equipment}

Staffing

Often, there is minimal staffing during the wildfire, and staff may not reach the hospital $(4,16)$. In a small, rural hospital, the dayshift staff continued to work, collaborating with the night-shift staff. The three Neonatologists on service remained in the NICU, while four other Neonatologists were available on standby (5). In a larger hospital, off-duty physicians arrived to begin discharging patients then joined with on-duty staff and physicians to evacuate patients (3).

On-duty staff at a larger hospital began calling off-duty staff, many of whom were unaware of the threat to the hospital. Those with families or homes imperiled by fire were conflicted with leaving family and home to return to work. Staff could not always reach the hospital in other wildland fires due to road closures (16). Fires change direction and speed in minutes; you can be safe with an escape route one moment, then cut off and endangered the next minute.

During a wildland fire event, one receiving NICU streamlined the vetting of NICU staff. Not every NICU was able to do so (16).

\section{Supplies and Equipment}

All facilities prepared a supply of current medications and necessary equipment for transport. Some neonatal staff obtained as 
many supplies as possible in preparation for an impending evacuation, one hospital specifically collecting formula bottles and nipples. Small emergency backpacks were discussed for emergencies with formula, wipes, diapers, and feeding tubes (16).

One facility described this extemporaneous process in some detail: A team of a clinical practice advisor, Neonatologist, and transport team nurse prepared an evacuation list of patient names, respiratory support, and equipment needs. Nurses then prepared transport bags of the necessary supplies for each baby. Important was the necessity of an isolette rather than a crib for transport. Staff members would transport patients using an isolette (5).

\section{Documentation}

In a series of wildland fires, infant identification became a concern by some of the hospitals. Besides ensuring the presence of an ID band on the infant, some suggested placing stickers on the infant's abdomen (16).

One NICU relied on an electronic medical record (EMR) shared by area hospitals (5). Two hospitals began copying medical records, keeping them on the nursing units though limited time caused some incomplete records $(3,4)$. Copying has delayed transfer in some cases (16). In other wildland fires, the receiving hospital did not have sufficient medical record documentation, or there was the incompatibility of the EMR (16).

\section{Problems Encountered}

For healthcare, a disaster is an environmental disruption of medical care that disrupts the ability to treat multiple patients. This is a functional, ecological definition (17). Environmental problems are not isolated but are embedded into each other - damaged structure, toxic air, cold temperatures, moving from one problem places the neonate into another.

Road conditions. Congestion from evacuating residents, fire burn over, and visibility impaired used of roads (3-5).

Smoke. Visibility from the smoke impaired recall of staff, surface transport of patients, and air operations. Hospital ventilation systems could not maintain clean air (3-5), with some hospitals using internal respiratory treatment stations (4).

Regional coordination. Neonatologists contacted receiving NICUs, and administrators coordinated transportation for the neonates. They did not have regional government coordination (5).

Equipment. It is not feasible to pack a bag at the moment for every patient (5).

Medical records. Some patients evacuated with incomplete records due to the limited preparation time (3).

Increasing staff. Staff requested more information as they balanced work, the safety of their family, a threat to their home, and the ability to travel on the roads to the hospital. Some were trapped in their neighborhoods. Some staff were called home to help the family. The fire trapped one nurse evacuating her family, resulting in a fatality and severe burns.

Communication. The hospital administration and NICU staff lacked a clear communication structure. Medical directors and physicians were not included in hospital incident command meetings. Medical staff leadership decided on evacuation while nursing leadership decided on shelter. The contradictory conclusions were communicated to their respective staff, creating confusion and exacerbating the tension of an intense situation (5). In a different wildland fire, neonates arrived at the receiving NICU without a call from the evacuating NICU asking for permission or providing a warning. Internet and phone call issues did not help. One participant had to text an intermediary to communicate (16).
Furthermore, the delegation of responsibilities was problematic. One participant said if they could have changed one thing, it would be to have a clear command structure in the unit $(1,16)$.

\section{Disaster Infrastructure}

A disaster brings together diverse infrastructures, but they are infrastructures of organizations and disciplines accustomed to collaborating (18). Viewed as relations, infrastructure builds a community. New for NICU sheltering or evacuation are the types of organizations and infrastructures they utilize. For example, air transport will be controlled by a central government agency, and FAA rules and procedures will become more visible. Boundary objects facilitate communication across disciplines and organizations while operating in a new boundary infrastructure (18).

\section{"You are not in one system or infrastructure - transport, emergency operations, and continuity of care have distinct infrastructures. Disaster infrastructure is new to the Neonatologist but well understood by disaster responders, hence the importance of boundary objects. There is a specific language and lexicon for risk within dangerous contexts that differ from medical care and business operations for disaster response."}

You are not in one system or infrastructure - transport, emergency operations, and continuity of care have distinct infrastructures. Disaster infrastructure is new to the Neonatologist but well understood by disaster responders, hence the importance of boundary objects. There is a specific language and lexicon for risk within dangerous contexts that differ from medical care and business operations for disaster response. There is a similar difference between stress versus capability, leadership, and what a leader does. The outlier is probably the most significant difference, whether an early herald or a random event. One person's infrastructure, however, can become another person's barrier (19).

\section{Lessons Learned}

The Lesson Learned process is a formal process that provides realistic, actionable recommendations that cause an organization to improve from the knowledge acquired after an adverse experience. It reduces or eliminates the potential for failures and mishaps or reinforces a positive result. Analytical processes discover what happened and why it happened. By identifying the root causes and remedial or corrective actions, experiences are transformed into best practices and lessons. Expert consultation from subject matter experts (SME) helps the organization understand the collected data to create informed recommendations (20).

The Lesson Learned must connect to measurable changes in behavior. The organization must take deliberate corrective actions from the Lesson Learned to enhance performance (20). Lessons Learned can prepare the organization for the next disaster or improve routine operations to support operations during the next disaster. 
Generally, a review of the published Lessons Learned reveals observations without analysis, nor do we find identified correctional actions or effective operations that should be reproduced.

\section{"All NICUs responded by improvising effective plans that fit situations in flux. Surveys of NICUs with experience with wildland fire also reflected the lack of significant gaps in response (16). Common traits identified in the above experiences and from other surveys were flexibility, adaptability, and remaining calm (16),"}

\section{The Lessons Learned}

All NICUs responded by improvising effective plans that fit situations in flux. Surveys of NICUs with experience with wildland fire also reflected the lack of significant gaps in response (16). Common traits identified in the above experiences and from other surveys were flexibility, adaptability, and remaining calm (16), traits necessary for decision making during emergencies $(21,22)$.

Smoke and poor air quality. Evacuation plans should include fire hazards, exposure to debris, and poor air quality (3). Despite 'air scrubbers' in place, air quality within the hospitals was poor with soot and debris $(3,4)$. Healthcare providers within the hospital were affected, and some experienced bronchospasm (4).

Evacuation. Identify methods to mobilize additional staffing, develop transportation options, and identify receiving hospitals (4). Evacuation time of 12 hours gave a calm, controlled process. In an emergent evacuation, specialized ambulance transport teams would have been used rather than accompanying neonatologists or bedside nurses (5). Medicating patients prior to transfer reduces difficulties in equipment (4) and medication administration by EMS personnel.

Impaired patient hand-off for the adult receiving hospital resulted when patients were transported with minimal medical information. Nurses counteracted this problem by nurse initiated RN-to-RN phone reports (3).

Communication. Prepare a script for on-duty staff to explain the crisis, reasons for the recall, and their responsibilities $(3,4)$. Improve the communication structure and include physicians in hospital incident command meetings. Inefficiencies and disconnections in communication interfered with the development of evacuation plans and preparation to evacuate $(3,5)$. Staff did not have clear guidance on when and where to report for duty or clarify their role and responsibility during a disaster (3).

Information. Keep everyone informed promptly. A stressful and intense situation with contradictory information from leaders becomes a major problem and source of confusion. "The realization that knowledge is power against panic" (5).

Incident command system. Develop an incident command communication workflow specific for NICU that connects to the hospital incident command $(5,23)$.

Social worker. Incorporate the NICU social worker into the disas- ter response rather than a social worker from an unfamiliar unit. The social worker, trusted and familiar to families, assists staff during the crisis (5).

Staff as victims. Identify methods to mobilize additional staffing. Staff, concerned about their families and homes, requested information necessary to return to work (4). Assist staff in developing family evacuation plans to decrease their worry (5). To return to, or stay at, work creates an untenable position between duty to protect patients and duty to protect (4).

Hospital as a haven. Residents arrived at the hospital with families and pets (3).

\section{Next Time}

Before the next fire season, develop a NICU-specific evacuation policy with procedures, have a quick triage method, and create easy-to-use checklists and supply lists. Conduct simulations for preparation or think through general scenarios for a framework to operate in a disaster (5).

The hospitals responded quickly to adapt medical care, prepare to evacuate, and identify personal conflicts for the caregivers (4).

All participants urge the use of drills for disaster preparation.

\section{Comment}

Disasters are the extension of routine operations - the NICU on the move into a dangerous environment, with trust in the emergency operations.

If healthcare providers are seriously affected in the hospital, consider the effect of air quality on the babies in the well-baby nursery and NICU. Also, consider that evacuation will expose neonates to smokey conditions, possibly for over an hour.

Staff as victims, the uninterrupted professional experience of disruption and loss while working continuously for 24-48 hours (5, 16) drains a person, compounded when the fire as personally experienced.

Healthcare providers and hospital workers may have at home young children, teenagers, or disabled dependents. To stay at the hospital would endanger their family members. Staff may need to remain at home or return home (4). Staff, supported by colleagues and hospital administration, returned to their homes and children during the Panorama Fire (CA) on Nov. 24, 1980.

Under even mild stress, we lose our prefrontal cortex abilities (24). Adolescents are the most susceptible. Their loss of PFC function is greater as they revert to an earlier childhood state while adults generally revert to middle adolescence.

In a wildland fire, staff may lose their homes or the life of a loved one. Staff told of colleagues who lost their homes to fire (16). Traveling during a disaster can become deadly. One nurse, evacuating with her family, was caught in the fire. Her daughter died, and another daughter suffered severe burns (4). Returning to duty immediately after the Northridge Earthquake, an LAPD officer died as he drove his motorcycle off a sheared-off freeway (25).

Evacuation. Physician orders are canceled when leaving hospital grounds. Paramedics operate under the medical control of their provider or a government agency. Nurses cannot administer medications unless the ambulance service employs them. RCPs and PAs do not exist in EMS law. They are considered civilians.

Triage system. Improvisation is effective. One NICU created its own system for evacuation priority, relying on their knowledge of the infants. This is similar to an improvised approach when paramedics triaged during a response to a terrorist shooting. Without the 'proper' colored triage tarps, they used salvage covers (the same material as a triage tarp but uncolored), placing the patients 
on the proper tarp, recognized by the treating and transporting paramedics. They did not use the sanctioned patient triage method (the START system) because it "becomes a mindless algorithm that can potentially under-triage and/or fail you and your patient." The use of the START system slowed triage and did not properly triage patients. It was quickly abandoned (26).

- Bedside nurses created supply bags for each neonate

- NICU extemporaneously created: "Pink, yellow, green."

- $\quad$ At the terrorist shooting, the truck company did not have the "appropriate" colored triage tarps. Firefighters used salvage covers, and all paramedics recognized the proper tarp. Even placing more urgent cases on one side of urgent compared to the other.

- After the school shooting, all teachers who evacuated went to the edge of the asphalt, which is their plan, then spontaneously walked their students to the back gate to the street.

Maternity ward. Treat all expectant mothers and infants as neonates. That is, treat the maternity nursery as a NICU.

"Fire behavior drives the NICU to simultaneously plan for evacuation and sheltering, with evacuation compromised by road conditions and visibility, while sheltering is compromised by air quality within the hospital and NICU. Regardless of regional or government plans, the NICU staff make specific decisions and preparations for evacuation or sheltering. "

\section{Conclusion}

Wildland fire can compromise evacuation routes and the use of vehicles, whether air or ground. Smoke-filled air endangers the neonate inside the NICU or riding in an ambulance. Rural hospitals several hours from a receiving hospital have but a few local ambulances available for evacuation. Poor visibility from smoke prevents helicopters from flying. Fire behavior drives the NICU to simultaneously plan for evacuation and sheltering, with evacuation compromised by road conditions and visibility, while sheltering is compromised by air quality within the hospital and NICU. Regardless of regional or government plans, the NICU staff make specific decisions and preparations for evacuation or sheltering. Personal relationships with area neonatologists helped obtain placement of neonates. Neonatologists and NICU staff extemporaneously created an effective, common-sense triage system.

\section{References:}

1. van Stralen D, McKay SD, Mercer TA. Disaster Series: The Abrupt Evacuation - Disasters without a Plan. Neonatology Today. 2021; In press.

2. van Stralen D, McKay SD, Mercer TA. Disaster Series: Prolonged Improvisation - High Reliability Organizing, the NICU, and Hurricanes. Neonatology Today. 2021; In press.

3. Barnett J, Dennis-Rouse M, Martinez V. Wildfire disasterleads to facilities evacuation. Orthop Nurs. 2009;28(1):17-20. Epub 2009/02/05. doi: 10.1097/01.NOR.0000345849.32424.0a. PubMed PMID: 19190472.

4. Hoyt KS, Gerhart AE. The San Diego County wildfires: perspectives of healthcare providers [corrected]. Disaster Manag Response. 2004;2(2):46-52. Epub 2004/05/11. doi: 10.1016/j.dmr.2004.04.001. PubMed PMID: 15133455.

5. Ma AL, Loughland MED, Lapcharoensap W, Dukhovny $D$, Lee HC. California and Oregon NICU Wildfire Disaster Preparedness Tools. Children (Basel). 2021;8(6). Epub 2021/07/03. doi: 10.3390/children8060465. PubMed PMID: 34206117; PubMed Central PMCID: PMCPMC8229531.

6. Spradley JP. Culture and Ethnography. In: Spradley JP, McCurdy DW, editors. Conformity and Conflict: Readings in Cultural Anthropology. 1st ed. Boston, MA: Pearson; 1984. p. 1-13.

7. Weick KE. Enactment and Organizing. The Social Psychology of Organizing. Second ed. New York, NY: McGraw-Hill, Inc.; 1979. p. 147-69.

8. Weick KE. The collapse of sensemaking in organizations: The Mann Gulch disaster. Administrative science quarterly. 1993;38(4):628-52.

9. van Stralen D, Inozu B, Byrum S. High Reliability for a Highly Unreliable World: Preparing for Code Blue through Daily Operations in Healthcare. North Charleston, SC: CreatSpace Publishing; 2017.

10. Phillips CB. California aflame! September 22-October 4, 1970. Sacramento, CA: Calif. Division of Forestry, 1971.

11. Butler BW, Bartlette RA, Bradshaw LS, Cohen JD, Andrews PL, Putnam T, et al. Fire Behavior Associated with the 1994 South Canyon Fire on Storm King Mountain, Colorado. Ogden, UT: Rocky Mountain Research Station, US Forest Service, 1998 Sept 1998. Report No.: Contract No.: RMRS$R P-6$.

12. Keller PA, Weick KE, Sutcliffe KM. Managing the unexpected in prescribed fire and fire use operations: A workshop on the High Reliability Organization. Ogden, UT: Rocky Mountain Research Station, US Forest Service, 2004 May 10-13, 2004. Report No.: Contract No.: RMRS-GTR-137.

13. Pyne S, Andrews $P$, Laven R. Introduction to wildland fire. 1996.

14. Sharples JJ, McRae RH, Weber R, Gill AM. A simple index for assessing fire danger rating. Environmental Modelling \&

NEONATOLOGY TODAY is interested in publishing manuscripts from Neonatologists, Fellows, NNPs and those involved in caring for neonates on case studies, research results, hospital news, meeting announcements, and other pertinent topics. Please submit your manuscript to: LomaLindaPublishingCompany@gmail.com 
Software. 2009;24(6):764-74.

15. NWCG NWCG. Fire Behavior Field Reference Guide. Boise, ID: National Interagency Fire Center, 2019 Contract No.: PMS 437.

16. Ma AL, Cohen RS, Lee HC. Learning from Wildfire Disaster Experience in California NICUs. Children (Basel). 2020;7(10). Epub 2020/10/07. doi: 10.3390/children7100155. PubMed PMID: 33019523; PubMed Central PMCID: PMCPMC7599616.

17. van Stralen D, McKay SD, Mercer TA. Disaster Series: Elements of a Disaster. Neonatology Today. 2021;16(10).

18. van Stralen D, McKay SD, Mercer TA. Disaster Series: Understanding Disasters - Classification and Infrastructure. Neonatology Today. 2021;16(10).

19. Star SL, Ruhleder K. Steps toward an ecology of infrastructure: Design and access for large information spaces. Information systems research. 1996;7(1):111-34.

20. Army US. Establishing a Lessons Learned Program: Observations, Insights, and Lessons. Learned CfAL, editor. Fort Leavenworth, KS: US Army Combined Arms Center; 2010.

21. van Stralen D, Mercer TA. Pragmatic High-Reliability Organizations (HRO) Modulate the Functions of Stress and Fear Behaviors During Pandemic COVID-19: The Stress-FearThreat Cascade. Neonatology Today. 2020;15(10):126-34. doi: 10.51362/neonatology.today/2020101510126134.

22. van Stralen D, Mercer TA. High-Reliability Organizing (HRO) in the COVID-19 Liminal Zone: Characteristics of Workers and Local Leaders. Neonatology Today. 2021;16(4):90-101. doi: 10.51362/neonatology.today/2021416490101.

23. van Stralen D, Fayard E, Paz J, Shelby L, Goldstein M, Merritt TA. Disaster Series: Disaster Planning for Perinatal/Neonatal Medicine: Rethinking the Process and Caring for Mothers. Infants and Technology Dependent Infants-The Time is NOW. Neonatology Today. 2021;16(10):9-22.

24. Arnsten AF. Stress signalling pathways that impair prefrontal cortex structure and function. Nat Rev Neurosci. 2009;10(6):410-22. Epub 2009/05/21. doi: 10.1038/nrn2648. PubMed PMID: 19455173; PubMed Central PMCID: PMCPMC2907136.

25. Kaplan T, Krikorian G. Other victims of the quake included a Los Angeles police officer who drove his motorcycle off a sheared-off freeway. Los Angeles Times. 1994 January 18, 1994.

26. van Stralen D, McKay S, Williams GT, Mercer TA. Tactical Improvisation: After-Action/ Comprehensive Analysis of the Active Shooter Incident Response by the San Bernardino City Fire Department December 2, 2015. San Bernardino, CA: San Bernardino County Fire Protection District; 2018.

Disclosures: The authors have no relevant disclosures

\section{NT}

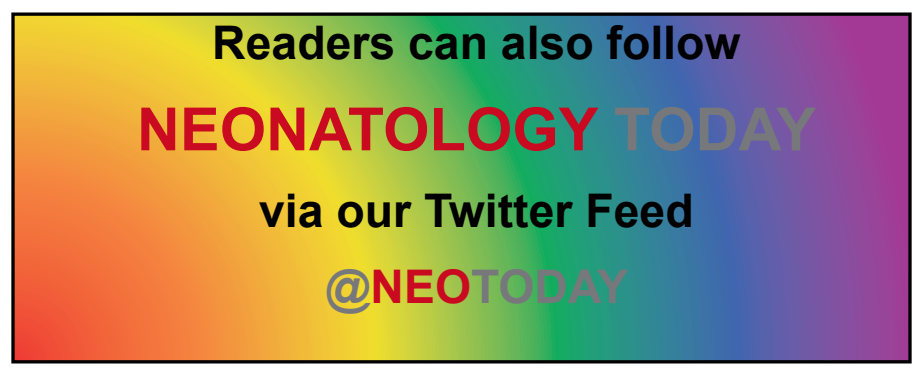

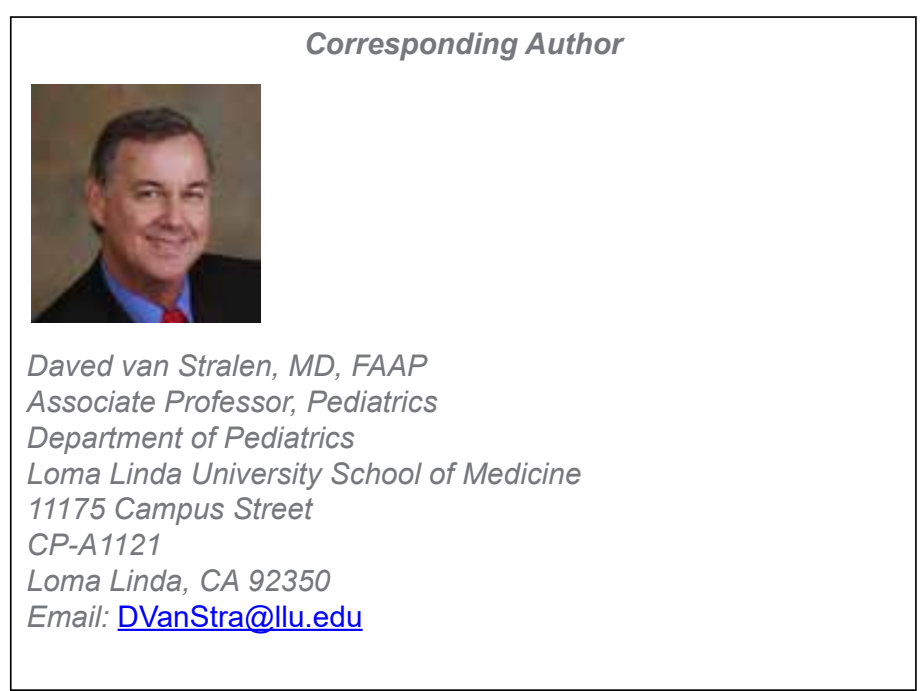

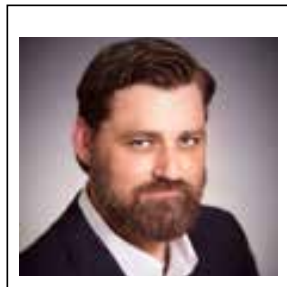

Sean McKay

Executive Partner / Director, Disruptive Rescue \& Austere Medicine

Element Rescue - Response Solutions within Nonlinear Complex Environments

Greenville, South Carolina, United States

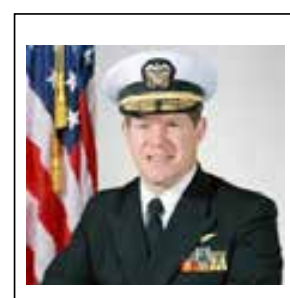

Thomas A. Mercer

Rear Admiral

United States Navy (Retired) 